\title{
Spot specimen testing with GeneXpert MTB/ RIF results compared to morning specimen in a programmatic setting in Cotonou, Benin
}

\author{
Faridath Massou ${ }^{1,2^{*}}$, Merlin Fandohan ${ }^{1}$, Ablo Prudence Wachinou' ${ }^{1}$ Schadrac Christin Agbla ${ }^{3,4}$, \\ Gildas Agodokpessi ${ }^{1}$, Leen Rigouts ${ }^{5}$, Bouke Catherine de Jong ${ }^{5}$ and Dissou Affolabi ${ }^{1,2}$
}

\begin{abstract}
Background: The diagnosis of tuberculosis (TB) using smear microscopy has been based on testing two specimens: one spot and one early morning sputa. Recently, the World Health Organization (WHO) has recommended to replace, whenever possible, microscopy with GeneXpert ${ }^{\circledR}$ MTB/RIF performed on a single specimen. However, as the bacterial load is higher in early morning specimens than in spot specimens, one could expect lower sensitivity of GeneXpert ${ }^{\circledR}$ MTB/RIF performed only on spot specimens. In this study, we compared results of GeneXpert ${ }^{\circledR}$ MTB/RIF on spot specimens versus early morning specimens, under programmatic conditions in Cotonou, Benin.

Methods: From June to September 2018, all sputa received from presumptive TB patients at the Supranational Reference Laboratory for Tuberculosis of Cotonou were included in the study. From each patient, two specimens were collected (one spot and one early morning) and GeneXpert ${ }^{\circledR}$ MTB/RIF was performed on both specimens.

Results: In total, 886 participants were included in the study, of whom 737 provided both sputa and 149 (16.8\%) gave only the spot specimen. For the 737 participants who provided both sputa, GeneXpert ${ }^{\circledR}$ MTB/RIF was positive for both specimens in 152 participants; for three participants GeneXpert ${ }^{\circledR}$ MTB/RIF was positive on spot specimen but negative on morning specimen while for another three, the test was positive on morning specimen but negative on spot specimen. The overall percentage of agreement was excellent (99.2\%) with a positive and negative percent agreement greater than $98 \%$.

Conclusion: For TB diagnosis under programmatic conditions in Cotonou, GeneXpert ${ }^{\circledR}$ MTB/RIF in spot specimens gave similar results with the test in morning specimens. Performing GeneXpert ${ }^{\circledR}$ MTB/RIF in both specimens did not significantly increase the number of cases detected. To avoid losing patients from the diagnostic cascade, it is preferable to test sputa produced at the time of the first visit at the health center.
\end{abstract}

Keywords: GeneXpert ${ }^{\circledR}$ MTB/RIF, Screening strategy, Specimens

\section{Background}

Tuberculosis (TB) is still a major public health concern especially in low resources settings. In 2019, among the 10 million of people affected, there were 1.4 million

*Correspondence: abenimas@gmail.com

${ }^{1}$ National Tuberculosis Program, NTP, Cotonou, Benin

Full list of author information is available at the end of the article deaths [1]. Since decades, the diagnosis of TB is standardized and based on World Health Organization (WHO)' recommendations, evolved over time to improve diagnostic services. In 2003, for screening in TB-endemic countries, WHO recommended for the diagnosis of pulmonary TB, the use of microscopic examination of two or three sputum specimens for detection of acid-fast bacilli (AFB) [2]. Indeed, several studies had shown that 
testing multiple specimens yields an increase in sensitivity compared to culture, the reference method for TB detection. This incremental yield was $11.1 \%$ for the second specimen (morning specimen, MS) compared to the first specimen (spot specimen, SS) and only $2-5 \%$ for the third specimen $[3,4]$. Moreover, the bacterial load of the MS was described to be higher than that of the SS [5-7]. WHO therefore recommended two specimens, including a MS, to diagnose pulmonary TB with microscopy in endemic countries $[8,9]$. Subsequently, nucleic acid amplification tests such as the GeneXpert ${ }^{\circledR}$ MTB/RIF (Cepheid, Sunnyvale, USA) have been developed. This new technology showed a higher sensitivity than microscopy, is user-friendly and results are available within $2 \mathrm{~h}$. In addition, it can detect resistance to rifampicin (RIF), the main first-line anti-TB drug $[10,11]$. WHO thus recommended in 2013 the use of GeneXpert ${ }^{\circledR}$ MTB/RIF as initial test for rapid and simultaneous detection of TB and RIF resistance in all TB suspected cases [12]. The recommendation supports the use of a single sputum but highlights that multiple specimens may increase the diagnostic sensitivity, yet recognizes resource implications. On the other hand, the preferred specimen between a SS and a MS especially in programmatic conditions in low income countries was not mentioned. Nevertheless, MS is associated with increased sensitivity of microscopy as initial diagnostic test. But to the best of our knowledge there are no studies evaluating in programmatic conditions the possible added value of the MS when GeneXpert ${ }^{\circledR}$ MTB/RIF is used as initial diagnostic test. One study evaluated the sensitivity of GeneXpert ${ }^{\circledR}$ MTB/ RIF test on MS versus SS and showed no significant difference. However, the study was restricted to smearnegative patients and the sample size was limited [13]. Furthermore, the possible impact of a screening strategy based on MS collection was not evaluated. In this study, we assessed the contribution of different specimens' collection strategies for pulmonary TB screening using GeneXpert ${ }^{\circledR} \mathrm{MTB} / \mathrm{RIF}$ in Cotonou, Benin.

\section{Methods}

\section{Study design}

Between June and September 2018, a prospective crosssectional study was conducted and included all consecutive patients with presumptive pulmonary TB (new and relapse cases).

\section{Study setting}

The study was carried out at the Centre National Hospitalier de Pneumo-Phtisiologie de Cotonou, the biggest public tertiary hospital specialized in TB in Benin. The hospital is located in the south of the country but also serves as referral center for the whole country.
Bacteriological diagnosis of TB in this hospital is performed by the WHO Supranational Reference Laboratory for TB in Cotonou, with a turnaround time of $24 \mathrm{~h}$ for the GeneXpert ${ }^{\circledR}$ MTB/RIF. Therefore, patients are asked to return to the clinic the day after the initial visit to obtain their result.

\section{Specimen collection}

After informed consent, patients were asked to provide two sputum specimens: the first one was collected on site (SS) and the second was provided the next morning after collection at home and brought to the laboratory (MS). A phone call was made to the patients who did not bring the MS.

\section{Specimen processing}

Specimens were processed with the GeneXpert ${ }^{\circledR}$ MTB/ RIF cartridge according to the manufacturer's instructions [14]. RIF-resistant results were further confirmed by repeating the test on an additional specimen as recommended for new cases [15]. Once confirmed as RIFresistant, this specimen was processed for culture and indirect phenotypic drug-susceptibility testing (pDST) on Löwenstein Jensen media $[16,17]$.

\section{Statistical analysis}

The overall percentage of agreement (OPA), positive percent agreement (PPA) and the negative percent agreement (NPA) with 95\% Wilson score confidence intervals were estimated to evaluate the performance of GeneXpert ${ }^{\circledR}$ MTB/RIF using SS and MS. The McNemar test was used to assess the evidence of agreement for GeneXpert ${ }^{\circledR}$ MTB/RIF results obtained from SS and MS. Subsequently, the Cohen's Kappa coefficient was used to evaluate the concordance between the bacterial load by GeneXpert ${ }^{\circledR}$ MTB/RIF and the type of sputum (SS or MS) [18]. All analyses were performed using Stata version 14.2 [19].

\section{Results}

In total, 886 presumptive TB patients were included in the study of whom $480(54.2 \%)$ were male, 859 (97.0\%) had never suffered from TB while $27(3.0 \%)$ had a history of TB (Additional file 1, Table 1). There was no evidence of difference in the distribution of age and history of $\mathrm{TB}$ across those who provided both SS and MS and those who only provided $\mathrm{SS}(\mathrm{p}=0.65$ and $\mathrm{p}=0.43$, respectively). However, women were more likely to return with a MS $(\mathrm{p}=0.02)$.

Of the 886 patients, 654 (73.8\%) returned to provide the MS as requested, while $83(9.4 \%)$ provided the MS after a reminder by phone, and the remaining 149 (16.8\%) did not provide it despite the phone call. Thus, 737 provided 
Table 1 Agreement between results from paired spot specimens (SS) and morning specimens (MS) using GeneXpert ${ }^{\circledR}$ MTB/RIF

\begin{tabular}{|c|c|c|c|c|c|c|c|}
\hline \multirow[t]{2}{*}{ Spot specimen } & \multicolumn{3}{|c|}{ Morning specimen } & \multirow[t]{2}{*}{$\mathrm{P}^{\mathrm{a}}$} & \multirow{2}{*}{$\begin{array}{l}\text { OPA } \\
(95 \% \mathrm{CI})^{b}\end{array}$} & \multirow{2}{*}{$\begin{array}{l}\text { PPA } \\
(95 \% \mathrm{CI})^{\mathrm{b}}\end{array}$} & \multirow{2}{*}{$\begin{array}{l}\text { NPA } \\
(95 \% \mathrm{CI})^{\mathrm{b}}\end{array}$} \\
\hline & Positive & Negative & Total & & & & \\
\hline Positive & 152 & 3 & 155 & 0.99 & 99.2 (98.2-99.6) & $98.1(94.5-99.3)$ & $99.5(98.5-99.8)$ \\
\hline Negative & 3 & 579 & 582 & & & & \\
\hline Total & 155 & 582 & $737^{\&}$ & & & & \\
\hline
\end{tabular}

OPA overall percentage of agreement; PPA positive percent agreement; NPA negative percent agreement

\& The agreement analysis included 737 presumptive TB patients who provided both SS and MS

${ }^{\text {a }}$ McNemar test

${ }^{\mathrm{b}}$ Wilson $95 \%$ confidence intervals

Table 2 Agreement between bacterial load of the positive specimens using GeneXpert ${ }^{\circledR}$ MTB/RIF on paired spot specimens and morning specimens

\begin{tabular}{llllll}
\hline Bacterial load from & \multicolumn{5}{c}{ Bacterial load from spot specimens } \\
\cline { 2 - 6 } morning specimens & High & Medium & Low & Very low & Total \\
\hline High & 28 & 24 & 4 & 1 & 57 \\
Medium & 6 & 45 & 14 & 2 & 67 \\
Low & 0 & 7 & 12 & 2 & 21 \\
Very low & 0 & 0 & 5 & 2 & 7 \\
Total & 34 & 76 & 35 & 7 & 152 \\
\hline
\end{tabular}

Kappa coefficient $=0.35$

both SS and MS and 149 provided only SS. Among the 232 patients who did not initially provide the MS, 37 (15.9\%; 95\% CI 11.2-20.7) had TB detected on the SS.

Agreement was evaluated using paired specimens only, thus in patients who provided both SS and MS. From 737 patients providing both SS and MS, 155 (21.0\%) were TB-positive by GeneXpert ${ }^{\circledR}$ MTB/RIF for both samples (Table 1). Using either SS or MS as reference standard, the PPA and NPA were $98.1 \%$ (95\% CI 94.5-99.3) and 99.5\% (95\% CI 98.5-99.8), respectively. The overall percentage of agreement was high (99.2\%, 95\% CI 98.2-99.6) and there was no evidence of disagreement between the two types of specimen $(\mathrm{p}=0.99)$. There were 731 concordant and six discordant results; the bacterial load ranged from "very low to medium" in the specimens that tested positive in either specimen type.

Comparing the bacterial load of paired SS and MS the kappa coefficient was 0.35 and suggested poor agreement between SS and MS (Table 2).

Finally, four RIF resistant (all were new cases) were detected on MS, of which two were also detected on SS (Table 3). The concordant RIF-resistant specimens had a bacterial load ranging from "high" to "low". The two discordant specimens had a "very low" bacterial load in MS while the bacterial load in SS was "low". After repeating
Table 3 Resistance status to rifampicin by GeneXpert MTB/RIF on paired spot specimens and morning specimens

\begin{tabular}{llll}
\hline Morning specimen & \multicolumn{3}{l}{ Spot specimen } \\
\cline { 2 - 4 } & Resistant & Susceptible & Total \\
\hline Resistant & 2 & $2^{*}$ & 4 \\
Susceptible & 0 & 148 & 148 \\
Total & 2 & 150 & 152 \\
\hline
\end{tabular}

*Confirmed as RIF-susceptible by repeat GeneXpert MTB/RIF and phenotypic drug-susceptibility testing

GeneXpert ${ }^{\circledR}$ MTB/RIF on an additional specimen, the two discordant specimens initially resistant by MS, were found RIF-susceptible with a "low" bacterial load. pDST confirmed all concordant results and RIF-susceptible results for the discordant cases.

\section{Discussion}

Of the included patients, more than a quarter did not provide the MS as per agreement, requiring a reminder by phone, which led to return to the clinic in a third of those who received the reminder. Under programmatic conditions, especially in low resources settings, an algorithm that includes a phone call to such a high number of presumptive patients may be difficult to implement because of economic implications and feasibility in routine conditions. Therefore, with a TB screening strategy based on GeneXpert ${ }^{\circledR}$ MTB/RIF on MS only, these presumptive patients could be lost. Moreover, $15.9 \%$ of these "loss to diagnostic follow-up" were diagnosed with TB. The MS-only strategy would be detrimental to global efforts to increase TB notifications. Indeed, giving a specimen at the hospital on the day of arrival probably creates a link between the patient and the hospital and motivates him/her to come back the next day to get the result. This is not the case with the MS-only strategy.

GeneXpert ${ }^{\circledR}$ MTB/RIF showed a similar positivity rate for SS and MS with excellent OPA, PPA and NPA greater 
than $98 \%$, which is consistent with what was previously reported [13].

Although the overall positivity rate on GeneXpert MTB/RIF ${ }^{\circledR}$ was similar, the poor agreement between the bacterial load of two types of samples suggests that the bacterial load of MS is higher than that of SS. This confirms previous studies' results based on microscopy which noted the superiority of MS over SS in terms of bacterial load [5-7]. Nevertheless, both sample types had the same number of "very low", so the difference was mainly in the grading of the samples with a higher bacterial load.

The overall high positivity rate observed in this study (21\% of presumed TB cases) could be explained by the fact that the study took place in a tertiary hospital for TB. Besides, it cannot be excluded that patients may have arrived late at the hospital in a deteriorated state of health.

The false negative cases noted in each group (SS and MS) could be explained by the intermittent nature of the bacilli released in sputum after cough that has been described in pulmonary TB patients [20]. Also the heterogeneous distribution of bacilli in the same specimen may have had impact, as the processed part may not contain any bacilli.

Among the four RIF-resistant cases recorded, two were false resistant. These discrepancies have been described as strongly associated with a "very low" bacterial load [21]. Indeed, the algorithm used to detect RIF resistance in GeneXpert ${ }^{\circledR}$ MTB/RIF is based on delay or absence of binding of five probes (labelled A-E) that cover the 81-bp RIF-resistance determining region. Thus, factors such as insufficient DNA in the specimen or silent mutation may lead to a false detection of RIF resistance [22]. To overcome these limitations, the GeneXpert ${ }^{\circledR}$ MTB/RIF Ultra has been introduced. In this cartridge, the detection of RIF resistance is based on the interpretation of the melting curves of molecular probes [23]. However, recent studies showed that for detection of RIF resistance, GeneXpert Ultra and GeneXpert ${ }^{\circledR}$ MTB/RIF had similar sensitivity and specificity $[24,25]$, and post-implementation population based studies are still to be performed. Another cause for the discrepant results could be the presence of minority rpoB mutant populations in the processed samples that were less fit to grow in culture, as was previously described for 'borderline' rpoB mutants [26]. While such mutations may be more frequently presenting as 'heteroresistance', which can easily be missed in GeneXpert (both MTB/RIF and Ultra requiring $>50 \%$ mutant population to recognize RIF resistance), they are not associated with lower bacterial burden than common rpo $B$ mutants. Needless to say, the interpretation of RIF resistance in the case of a very low bacterial load should be done with great care and should follow published guidelines [15].

\section{Conclusion}

In conclusion, both SS and MS yielded similar rates of TB diagnosis by GeneXpert ${ }^{\circledR}$ MTB/RIF in presumptive patients, but a screening strategy based on MS may lead to loss to follow up of patients. SS is therefore suitable as initial sample for TB diagnosis by GeneXpert ${ }^{\circledR}$ MTB/RIF.

\section{Abbreviations}

MS: Morning specimen; NPA: Negative percent agreement; OPA: Overall percentage of agreement; SS: Spot specimen; PDST: Phenotypic drug susceptibility testing; PPA: Positive percent agreement; TB: Tuberculosis.

\section{Supplementary Information}

The online version contains supplementary material available at https://doi. org/10.1186/s12879-021-06676-6.

Additional file 1: Table 1. Participants' characteristics by number of specimens provided.

\section{Authors' contributions}

FM, MF, APW, GA and DA contributed to the conception of the study and its design. SCA performed the statistical analysis. FM wrote the first draft, BCdJ, LR and DA reviewed and edited the manuscript. All the authors revised the draft, provided critical comments, and have agreed to be personally accountable for the author's own contributions. All authors read and approved the final manuscript.

\section{Funding}

This research did not receive external funding.

\section{Availability of data and materials}

The datasets used during the current study can be obtained from the corresponding author on request.

\section{Declarations}

\section{Ethics approval and consent to participate}

The study was approved by the Ethics Committee of the Faculty of Health Sciences of Cotonou of the University of Abomey-Calavi, Benin ( $N^{\circ} 011-18$ / UAC/FSS/CER-SS). Informed consent was obtained from all subjects involved in the study.

\section{Competing interests}

The authors declare no competing interests.

\section{Author details}

${ }^{1}$ National Tuberculosis Program, NTP, Cotonou, Benin. ${ }^{2}$ Supranational Reference Laboratory for Tuberculosis of Cotonou, Cotonou, Benin. ${ }^{3}$ London School of Hygien and Tropical Medicine, London, UK. ${ }^{4}$ University of Liverpool, Liverpool, UK. ${ }^{5}$ Institute of Tropical Medicine, Antwerp, Belgium.

Received: 2 August 2021 Accepted: 8 September 2021

Published online: 20 September 2021

\section{References}

1. World Health Organization (WHO). Global tuberculosis report. Geneva: World Health Organization (WHO); 2020. 
2. Organisation Mondiale de la Sante (OMS). Le traitement de la tuberculose: principes à l'intention des programmes nationaux. Geneva: Organisation Mondiale de la Sante (OMS); 2003.

3. Mase SR, Ramsay A, Ng V, Henry M, Hopewell PC, Cunningham J, et al. Yield of serial sputum specimen examinations in the diagnosis of pulmonary tuberculosis: a systematic review. Int J Tuberc Lung Dis. 2006;2007(11):485-95.

4. Leonard MK, Osterholt D, Kourbatova EV, Rio D, Wang W. How many sputum specimens are necessary to diagnose pulmonary tuberculosis? Assoc Prof Infect Control Epidemiol. 2005;33:58-61.

5. Sarin R, Mukerjee S, Singla N, Sharma PP. Diagnosis of tuberculosis under RNTCP: examination of two or three sputum specimens. Indian J Tuberc. 2013;48(13):2-5

6. Van DA, Salim AH, Cooreman E, Hossain A, Rema A, Chambugonj N, et al. Optimal tuberculosis case detection by direct sputum smear microscopy: how much better is more? Int J Tuberc Lung Dis. 2002;6(3):222-30.

7. Gopi PG, Subramani R, Selvakumar N, Santha T, Eusuff SI, Narayanan PR. Smear examination of two specimens for diagnosis of pulmonary tuberculosis in Tiruvallur District, south India. Int J Tuberc Lung Dis. 2004:8(7):824-8

8. World Health Organization (WHO). Treatment of tuberculosis: guidelines. 4th ed. Geneva: World Health Organization (WHO); 2010.

9. Tuberculosis Coalition for Technical Assistance. International standards for tuberculosis care (ISTC). 2nd ed. The Hague: Tuberculosis Coalition for Technical Assistance; 2009.

10. Steingart KR, Schiller I, Horne DJ, Pai M, Boehme CC, Dendukuri N. Xpert ${ }^{\circledR}$ MTB/RIF assay for pulmonary tuberculosis and rifampicin resistance in adults (review) Xpert ${ }^{\circledR}$ MTB/RIF assay for pulmonary tuberculosis and rifampicin resistance in adults. Cochrane Libr. 2014;1:1-3.

11. Van Zyl-Smit RN, Binder A, Meldau R, Mishra H, Semple PL, Theron G, et al. Comparison of quantitative techniques including Xpert MTB/RIF to evaluate mycobacterial burden. PLoS ONE. 2011;6(12):e28815.

12. World Health Organization (WHO). Xpert MTB/RIF assay for the diagnosis of pulmonary and extrapulmonary TB in adults and children TB. Geneva: World Health Organization (WHO); 2013.

13. Tadesse M, Aragaw D, Rigouts L, Abebe G. Increased detection of smearnegative pulmonary tuberculosis by GeneXpert MTB/RIF ${ }^{\circledR}$ assay after bleach concentration. Int J Mycobacteriol. 2016;5(2):211-8. https://doi. org/10.1016/j.jijmyco.2016.03.005.

14. Boehme CC, Nabeta P, Hillemann D, Nicol MP, Shenai S, Krapp F, et al. Rapid molecular detection of tuberculosis and rifampin resistance. N Eng J Med. 2010:363(11):1005-15.

15. Global Laboratory Initiative (GLI). GLI model TB diagnostic algorithms. 2018
16. World Health Organization (WHO). Drug resistance profiles of catalogue of mutations in Mycobacterium tuberculosis complex and their association with drug resistance. Geneva: World Health Organization (WHO); 2021.

17. Canetti G, Froman S, Grosset J, Hauduroy P, Langerova M, Mahler HT, et al. Mycobacteria: laboratory methods for testing drug sensitivity and resistance. Bull World Health Organ. 1963;29:565-78.

18. Altman DG. Practical statistics for medical research. London: Chapman \& Hall/CRC; 1999

19. StataCorp. Stata statistical software: release 14. College Station: StataCorp LP.; 2015.

20. Patterson B, Wood R. Is cough really necessary for TB transmission? Tuberculosis. 2019;117(May):31-5. https://doi.org/10.1016/j.tube.2019.05.003.

21. Ngabonziza JCS, Decroo T, Migambi P, Habimana YM, Van Deun A, Meehan CJ, et al. Prevalence and drivers of false-positive rifampicin-resistant Xpert MTB/RIF results: a prospective observational study in Rwanda. Lancet Microbe. 2020;1(2):e74-83. https://doi.org/10.1016/S2666-5247(20) 30007-0.

22. Ocheretina O, Byrt E, Mabou M, Royal- G, Merveille Y, Rouzier V, et al. Falsepositive rifampin resistant results with Xpert MTB/RIF version 4 assay in clinical samples with a low bacterial load Oksana. Diagn Microbiol Infect Dis. 2016;85:53-5. https://doi.org/10.1016/j.diagmicrobio.2016.01.009.

23. Dorman SE, Schumacher SG, Alland D, Nabeta P, Armstrong DT, King B, et al. Articles Xpert MTB/RIF ultra for detection of Mycobacterium tuberculosis and rifampicin resistance: a prospective multicentre diagnostic accuracy study. Lancet Infect Dis. 2017;3099(17):1-9.

24. Zifodya J, Kreniske J, Schiller I, Kohli M, Dendukuri N, Schumacher S, et al. Xpert ultra versus Xpert MTB/RIF for pulmonary tuberculosis and rifampicin resistance in adults with presumptive pulmonary tuberculosis. Cochrane Database Syst Rev. 2021. https://doi.org/10.1002/14651858. CD009593.pub5.

25. Opota O, Greub G, Jaton K. The rapid molecular test Xpert MTB/RIF ultra: towards improved tuberculosis diagnosis and rifampicin resistance detection. Clin Microbiol Infect. 2019. https://doi.org/10.1016/j.cmi.2019. 03.021.

26. Torrea G, Ng KCS, Van Deun A, André E, Kaisergruber J, Ssengooba W, et al. Variable ability of rapid tests to detect Mycobacterium tuberculosis rpoB mutations conferring phenotypically occult rifampicin resistance. Sci Rep. 2019:9(1):1-9.

\section{Publisher's Note}

Springer Nature remains neutral with regard to jurisdictional claims in published maps and institutional affiliations.
Ready to submit your research? Choose BMC and benefit from:

- fast, convenient online submission

- thorough peer review by experienced researchers in your field

- rapid publication on acceptance

- support for research data, including large and complex data types

- gold Open Access which fosters wider collaboration and increased citations

- maximum visibility for your research: over $100 \mathrm{M}$ website views per year

At BMC, research is always in progress.

Learn more biomedcentral.com/submissions 